\title{
Must There Be Basic Action?
}

\section{Citation}

Lavin, Douglas. 2012. Must there be basic action? Noûs.

\section{Published Version}

doi:10.1111/j.1468-0068.2012.00876.x

\section{Permanent link}

http://nrs.harvard.edu/urn-3:HUL.InstRepos:9637987

\section{Terms of Use}

This article was downloaded from Harvard University's DASH repository, and is made available under the terms and conditions applicable to Open Access Policy Articles, as set forth at http:// nrs.harvard.edu/urn-3:HUL.InstRepos:dash.current.terms-of-use\#OAP

\section{Share Your Story}

The Harvard community has made this article openly available.

Please share how this access benefits you. Submit a story.

\section{Accessibility}


Must There Be Basic Action?* (forthcoming in Nous)

Douglas Lavin

Harvard University

Although a divine agent can perhaps simply say "Let there be light" and thus there is light, our sort of life is a bit more of a struggle, requiring us to do various things in order to get much of anything done. Consider illuminating a room, building a house, or baking a cake. How do we execute complex projects such as these? The answer, says contemporary action theory, is that we perform complex actions by performing a more or less intricate sequence of basic actions, while we perform basic actions immediately, directly or "just like that." Arthur Danto gave early expression to this way of thinking about the structure of action: "A basic action is perfectly simple in the same sense in which the old 'simple ideas' were said to be: they were not compounded out of anything more elementary than themselves, but were instead the ultimately simple elements out of which other ideas were compounded." 1 The thought here is that the practically complex resolves into the practically simple as a digital image resolves into a highly structured set of color points, or as a digital recording resolves into a series of discrete sonic atoms. And my aim in this paper is to raise some doubts about this practical atomism and to say something about why it matters whether it is true.

Dependence, mediacy, and complexity are abstract concepts, as are their complementary opposites, independence, immediacy, and simplicity. The determinate conception we have to do with here is of an instrumentally or teleologically basic action: very roughly, an action is basic in this sense when no means are taken in its execution, or equally, when it is not the end of any other action. The concept figures in the description of the structure of getting something done, specifically of getting something done on purpose or intentionally, and thus also in the description of the agent's point of view on the structure of his own efficacy. The agent so depicted understands himself as doing whatever he does through the performance of basic actions, with all the rest derived from these. Means-end rationality expands our sphere of influence and massively extends our reach — there are flags on the moon and at the bottom of the sea! - but it is precisely at the inner limit of this teleological order that a rational agent's power to make a dent in things is genuinely displayed. Where means-end rationality comes to a close, efficacy 
genuinely begins: this is where the conceptual rubber is supposed to hit the material road, in the things one does without thought about how they get done. Sometimes it is said there is a spark of the divine in this. My own view is the opposite, that there is at best only a shadow of the brute. 2

The idea of basic action is a fixed point in the contemporary investigation of the nature of action. And while there are arguments aimed at putting the idea in place, it is meant to be closer to a gift of common sense than to a hard-won achievement of philosophical reflection. It first appears at the stage of innocuous description and before the announcement of philosophical positions. And yet, as any decent magician knows, the real work so often gets done in the set-up. I argue that the seemingly innocent idea of basic action is, in fact, bound up with a wide-spread conception of the nature of bodily or physical action (section 3). Its legitimacy is vital to the intelligibility of the causal theory of action, according to which physical action consists of a mere event and a condition of mind joined (in the right way) by the bond of causality. Left unchecked, means-end reason threatens to permeate physical action, and thus threatens the sovereignty of the sphere of material events at the center of the causal theory: such events, including the movements of one's body when one intentionally moves it, are thought to be constitutively independent of the subject's rational capacities. Basic action is a necessary countermeasure, a sort of metaphysical containment wall needed to preserve the separate jurisdictions of the mind of the acting subject and what merely happens.

I argue that so long as action theory proceeds under the assumption that there must be basic action, it must regard our relation to the progress of our own deeds as not different in principle from Marx's understanding of the relation of the non-worker (Nichtarbeiter) to the material processes that realize his own ideas, namely the work done on the factory floor.3 Each is alienated from the progress, or getting done, of his deeds. In each the process of doing something intentionally turns out to be a case of delegating tasks to another power. How the process comes to completion is not willed, and at best watched: the causal work is not the agent's work, his knowledge not self-knowledge (section 5). We should find this unacceptable. And if this is right, it should be a pressing question whether there must be basic action. I argue that we have no good reason to think so: basic action is not forced on us by argument (sections 2 and 4). It is open to us to consider an alternative, one on which action is not, in the fundamental case, barren of means-end 
structure, but instead permeated by it: we register as a force in nature not at the limit of the means-end order but precisely in its constitution.

This change of orientation has general implications for the metaphysics of agency, not simply because it disturbs the foundation of the causal theory, but because it is itself a partial articulation of a conception of action as a categorically distinctive form of event or process. Here doing something intentionally is not an event of some generic kind with certain special causes, but instead an event that is inextricably both material and conceptual. In giving up on basic action, the means-end order is shown to be at once an order of causality (the means realize the end) and an order of reason (the end rationalizes the means). And this order, an order of practical reason, is shown to be internal to what happens, to the progress of the deed itself. However, I do not get much beyond ground clearing here.

\section{What is Basic Action?}

The expression "basic action" is plainly a term of art. Many meanings have been attached to it. I do not want to quarrel over its use. And I do not want to deny that there are legitimate sources of the widespread, though sometimes inchoate, intuition that there are or must be elementary practical operations, "basic actions" — things we do "just like that" - in some sense or other. (I say something about these sources and the specific ideas they lead to in section 4). Nevertheless, I will be concerned with a very specific idea answering to the expression: it is the idea of teleological basicness. 4 What I propose to do now is to isolate this conception of an elementary practical operation.

I move my finger, flip the switch, turn on the light, and illuminate the room. This might be a report of four independent actions, an undifferentiated bundle or mere aggregate $(A, B, C, D)$. Or it might be a report of a temporal sequence of otherwise independent actions, like entries in a diary (A and then $\mathrm{B}, \mathrm{B}$ and then ... . ). But we do not have the case as Donald Davidson imagines it, and as it concerns us here, unless these are bound together as the elements of an explanatory order of means and ends: I do A, I do B, and, moreover, doing the one accounts for doing the other. Among actions so related, the end is why the means are taken (Why are you flipping the switch? I'm flipping it in order to turn on the light), and the means are how the end is realized (How are you turning on the light? I'm turning it on by flipping the switch). The question "Why?" that elicits the meansend 
order bears Anscombe's special sense and is tied to a certain sense of "How?", a question also eliciting that order and also articulating the point of view of the agent, though here not on the agent's reasons but on his efficacy. 5

Basic action is a limit on this rational order of means and ends. It can be described from either side of the relation. Through the concept of an end: a basic action is not the end of any other action; nothing else is done in order to do it; it is not an answer to "Why?" when asked about any other action. And equally through the concept of a means: no means are taken in the execution of a basic action; it is not done by doing anything else; there is no answer to "How?" when asked of it. I illuminated the room by means of turning on the light, turned on the light by flipping the switch, and flipped the switch by moving my finger, but maybe moving my finger is something I simply did, something which did not involve taking any steps or means, or again doing anything with a view to moving my finger? If so, it is a basic action: That $\mathrm{X}$ is doing/did $\mathrm{A}$ is basic just when there is no $\mathrm{A} *$ such that $\mathrm{X}$ is doing/did $A *$ in order to do $A$; or again, That $X$ is doing/did $A$ is basic just when there is no $A *$ such that $X$ is doing/did $A$ by means of doing $A *$. Quite generally, rational agency is the capacity to apply thought to action: it is the capacity to do things for reasons or on the basis of considerations. In the canonical formulation of the consideration on which an agent acts, the agent is described as thinking that there is something about doing $A$ and in light of this does $\mathrm{A}$. In the specific case of instrumental agency, the thought about $\mathrm{A}$ is always that it has some relation to $\mathrm{B}$, something else the agent aims to do, say, that it will be sufficient for doing $B$, or that it is necessary for doing B, or even only that it will facilitate doing B.6 Since a basic action is, by definition, not mediated by the performance of any other action, it is not mediated by any such thought — thought about how to bridge the gap between here, where one has not yet done what one aims to do, and there, where one has brought things to completion. With basic action, thought about how to realize the end in question gives out — one acts immediately, directly or "just like that."

The classification of actions into the basic and the non-basic is not meant to be merely one among many ways of carving up what is done intentionally, as are classifications of actions according to whether or not one is done with the eyes open or on Tuesday. The classification is meant to be one we must recognize if we are to understand the very structure of intentionally doing 
something: whatever large-scale projects one has realized though the ordering of means to ends, one must eventually reach a fine enough resolution and come upon things that have been done without any thought about how to get them done. This bare-bones depiction of the structure of practical or productive consciousness is not meant to be, in the first place, the upshot of theoretical investigation, but instead part of the pre-theoretical scaffolding on which our researches into the nature of action take shape: its apparently unproblematic inevitability rests on its being placed among the innocent preliminaries. The model is pervasive. But does it really have all the authority of common sense?

\section{A Preliminary Challenge: Find the Basic Action}

When I think about my own case, I have to confess that I have a hard time finding the basic ones. What have I done just like that?

Suppose I am on the road to Kathmandu with Donald Davidson. "Stop! Don't turn left. We've got to go this way," I say, pointing to our position on the map, Chitwan, and then tracing the improbably straight path, arranged for philosophical purposes, of an unnamed road all the way to Kathmandu. What is the basic action in all this? Now, I intentionally moved my finger along the line from Chitwan to Kathmandu. And I also have moved my finger from Chitwan to here, Hetauda, which is halfway along the route. Indeed, I did this intentionally and with a view to moving it to Kathmandu. But of course I have also moved my finger from Chitwan to here, mid-point on the way to Hetauda. And why shouldn't it also be that I did this intentionally and with a view to moving it to Hetauda and so in order to move it to Kathmandu? After all if you point it out, I won't say "I didn't know I was", and moreover I will be able to give the reason why I was doing it. And, now, what is to prevent us from applying this procedure again and again without end, each time isolating some initial segment of a movement and showing it to be something I did with a view to bringing off the whole?7

The general challenge here is to take some actual intentional action A, an action performed on a particular occasion, and to point to one of its basic parts. The difficulty is to find a describable part of $A, A *$, which is something the agent did intentionally in order to do A, but which does not itself resolve into further sub-actions that the agent did intentionally in order to do $\mathrm{A} *$. This challenge to find the basic action is not meant to be decisive, only suggestive, and to get us to wonder about the ground of our confidence 
that there is or must be basic action. If one does wonder, as I do, then the situation looks like this: there is a general philosophical consensus that basic action is the core of any action whatsoever, yet it is difficult, or at least more difficult than one might have expected, to discern particular cases of basic action. This forces the question why exactly we think that there is or must be basic action in the first place. What is supposed to convince us of this thing that we can't exactly find when we go looking for it? Before looking into the reasons and arguments, however, I want to say something about why we might care about this.

\section{What Merely Happens}

The only feature of contemporary action theory as pervasive as the idea of basic action is the use of Wittgenstein's question to set the terms of the discussion: "Let us not forget this: when 'I raise my arm', my arm goes up. And the problem arises: What is left over if I subtract the fact that my arm goes up from the fact that I raise my arm?" 8 For our purposes, whether Wittgenstein sincerely means to answer it does not matter; what matters is the widespread tendency to pursue the investigation of action through it. It matters because the question itself forces a certain shape on subsequent reflection. It insists that the theory of action be a search for a solution to this equation: action (or again, doing something intentionally) consists of a not-intrinsically-intentional physical event, a mere happening, occurring in a context where certain further facts obtain.

In physical or bodily action things happen in the objective world: when I raise my arm, my arm goes up, and when I move a book, the book moves. My arm's going up, the book's moving - these are, of course, physical happenings, elements of the observable world of matter in motion. A presupposition of Wittgensteinian arithmetic is that such happenings are constitutively independent of a subject's rational capacities - they are what they are regardless of what or whether anyone thinks.9 The material processes underway or happening when one is acting, especially including the movements of one's body when one is intentionally moving it, are not intrinsically intentional. Rational purposiveness is to be understood in terms of their standing in external relations to something else. Indeed, very much of the dispute within mainstream action theory is over how to specify the something else (beliefs, desires, intentions, policies, acts of will, the agent herself, others?), and how to characterize the sort of relation (event causal, agent causal, triggering, 
structuring, sustaining, others?) joining this to what merely happens.

The standard story of action says: I raised my arm when my arm's rising is caused in the right way by certain psychological occurrences with relevant contents. Here is Michael Smith: "Actions are those bodily movements that are caused and rationalized by a pair of mental states: a desire for some end, where ends can be thought of as ways the world could be, and a belief that something the agent can just do, namely, move her body in the way to be explained, has some suitable chance of making the world the relevant way." 10 The standard story operates with a generic conception of the causal order, the order in which things happen because of other things. It aims at an understanding of acting, making things happen for reasons, as a matter of certain elements being related in the only way that bears on why anything happens. There are many, like Smith, who think a psychology of beliefs and desires is too impoverished to account for some of the more sophisticated manifestations of our own agency, but who are nevertheless committed to this naturalistic agenda and who proceed by extending the initial model, typically by supplementing the kinds of psychological occurrence that figure as causes. 11 The typical complaint about the standard story (and any of its extensions) is that it leaves the agent out-depicting only a locus of psychological transactions but not a genuine source of reasoned activity - and thus cannot capture the essentially self-determined character of doing something intentionally. Non-standard stories of action hope to offer a corrective by placing something irreducibly "active" at the origin of the physical happening and say: I raised my arm when my arm's rising is caused in the right way by an act of will or by the agent himself. Here is John Bishop: "All intentional actions have a component which is a basic action, and it is here that the agent-causalist professes to find an irreducible causal relation between agent and event." 12 But whatever the specific disputes, the parties to them share a generic conception of a material process or event (the conditions of identity and individuation are free of intentionality) and the explanatory ambition of fitting action into a world of material processes so understood. And thus they share an allegiance to the very general framework of the causal theory of action: that X did A intentionally is the arithmetic sum of what merely happens and something else.

Anyone familiar with the literature in this part of action theory, the part representing standard and non-standard stories, should be struck by the ubiquity of appeal to the notion of basic action. It seems to sit at the center 
of these otherwise very different pictures of the constitution of physical action. Consider the passage from Smith above. What an agent "can just do" is what an agent can do without having to take any intentional steps or means: the performance of such a thing is (typically) a basic action in our sense. Whatever modifications might be made to the standard story, and however sophisticated it might become, what is crucial for our purposes is that basic action remains the fundamental manifestation of agency. And, as the passage from Bishop indicates, the concept of basic action is not simply a tool for those who build upon the standard story. 13 Indeed, the dispute between standard and non-standard stories is about whether we can do without the metaphysical extravagance of an act of will or the agent in our understanding of basic action. In such a case, is the source or cause of what happens a complex of psychological states and events, an act of will, or simply the agent herself? The problem of action is here the problem of basic action, and the philosophy of action the philosophy of basic action.

Why do those who hold a decompositional conception of action so consistently appeal to basic action? Why, that is, do they consistently think that the fundamental manifestation of agency appears at the inner limit of the rational ordering of means and ends? I believe this correlation is not an accident. Basic action in our specifically teleological sense does crucial and indispensible work for the causal theory: the viability of the conception of physical action as a composite of an independently intelligible external happening and further conditions depends on the availability of the concept of basic action. If the connection has hardly been discussed, that is only because dependence on something regarded as so innocent can hardly register as a topic for explicit reflection. It is important to articulate the connection nevertheless.

The currency of our ordinary representation of action is a certain class of simple sentences (e.g. "Jones turned on the light," "I am making an omelet") in which the representation of an act-form ("to turn on the light," "to make an omelet") is immediately joined to the representation of an agent ("Jones," "I"). These are, after all, terms in which we ask and answer the reason-seeking why-question (I did A. Why? I am doing B.) and the efficacy-articulating how-question (I am doing B. How? I am doing A). Now, the causal theorist is happy to speak in such terms for ordinary purposes. But how are we to understand them? What are the fundamental commitments implicit in such talk and thought? Of course, the causal theorist resists taking ordinary reports of 
doing something intentionally to be representations of a distinct, intrinsically intentional form of material process. Davidson warns us, for example, not to be deceived by the adverbial form of "intentionally": "intentional actions are not a class of actions [or movements], or, to put the point a little differently, doing something intentionally is not a manner of doing it."14 Common thought and talk of action concerns, instead, what merely happens and further conditions. But since ordinary practical representations do not explicitly mention or refer to what merely happens_-sometimes called the "result of" or "event intrinsic to" an action-the first step in subjecting action to a decompositional analysis is to isolate this element. And my thought is that without basic action this crucial first step could not be taken: a residue of intentionality would always remain in the representation of material processes themselves, of movements as movements. It will not be possible to realize the explanatory ambition of the causal theory, namely to fit action into a world that does not contain intrinsically intentional material processes, unless basic action is the fundamental manifestation of rational agency.

What does it consist in that $\mathrm{X}$ did $\mathrm{A}$ when this is a non-basic action? On anyone's view, it consists in X's having done other thing(s) intentionally; these subordinate actions, the means, are that through which $\mathrm{X} \operatorname{did} \mathrm{A}$. There are different forms of means-end connection, or ways in which means contribute to the realization of an end. In one sort of case, the staple of contemporary action theory's diet of examples, someone does something that, in the circumstances, is enough to do some other thing, e.g. Jones flipped the switch and in so doing he turned on the light. In another sort of case, that X did A (non-basically) consists in a series of actions no one of which is enough for success: I broke some eggs into a bowl, seasoned and stirred, then I poured the mixture into a pan, I let it sit for one minute, added cheese and scallion, and then flipped the egg pancake . . . et cetera, voila. I made an omelet in doing these other things. Now, it would not discharge the causal theorist's burden of isolating what merely happens simply to point out that when Jones turned on the light intentionally, the light's going on was caused by Jones' intention to turn on the light. For this causal connection rests on the following connection: Jones flipped the switch intentionally with the result that the light went on. Likewise it would not discharge the causal theorist's burden simply to point out that an omelet's coming into existence was caused by the agent's intention to make an omelet. For again this causal connection rests on complex connections between the several intentional 
actions that contribute to the omelet making. In each case, the analysis of non-basic action has left us with an unanalyzed residue that itself consists of one or more intentional actions. Thus the causal theorist has not yet isolated the not-intrinsically-intentional events whose causation in the right way can constitute intentional action. If all actions were non-basic, the causal theorist's analytical strategy would never yield what the theory demands: a mere happening whose causation by certain conditions of mind is acting intentionally.

Basic action is what stops this regress. If " $\mathrm{X}$ did A" reports a basic action, then, ex hypothesi, X's doing A does not involve X's having done anything else intentionally. Here, finally, we have an action which might itself be identified with non-intentional movement caused by thought. Here, we reach a practical atom, something that might be shown to stand as the correlate of a mere happening. Of course, with the basic case in place the causal theory will extend the analysis by describing how non-basic action ultimately decomposes into an aggregate of basic actions, caused by intentions with such-and-such contents, which can themselves be decomposed into independently intelligible, metaphysically independent, internal and external elements, the mind of the acting subject and what merely happens. 15

Let me step back from the details of the argument to say in very rough terms why I take the idea of basic action to come so naturally to those who think of material processes or movements in general, and thus of such movements as figure in physical action, as constitutively independent of thought. In general, philosophical conceptions of the objective, material world tend to proceed in parallel with conceptions of human subjectivity and the mind. The generic conception of a material process which makes the decompositional conception of intentional action seem compulsory is reflected in a certain conception of the mind, specifically of the mind in a practical relation to the world. Here, thought or reason must stop short of movement itself: it cannot reach all the way into the constitution of what happens. 16 If the jurisdiction of practical thought must be so limited, so must the jurisdiction of specifically instrumental thought, the rational ordering of means to ends - there must be basic action.

\section{Must There be Basic Action?}

In section 2, I questioned the force of arguments for basic action that appeal to a putatively direct and intuitive awareness of them. But the deep attraction 
of the thought that there are basic actions comes from elsewhere. It stems, I think, from a sense that there must be, if there is to be any action at all: some of my actions depend on others for their occurrence, but not every action can depend on another, on pain of regress. But what exactly is the regress, and why is it vicious?

In this section, I consider two attempts to develop the thought that basic action is necessary to halt a regress. On the first, the need for basic action grows out of reflection on the causal character of certain action concepts. On the second, the need for basic action grows out of reflection on the general character of practical cognition. In response to each, I want to agree that the regress argument locates a genuinely attractive idea, one that might answer to a sense that there must be elementary practical operations of some sort or other. But I then want to claim that the regress argument does not establish that there must be basic action in our specifically teleological sense and thus cannot do the metaphysical work required by the causal theory.

\section{The regress of causes}

Sometimes an agent's doing something (the officer sank the Bismarck) can be understood as her causing something to happen (the officer caused the Bismarck's sinking), where this can be understood in terms of a relation between action and upshot- - her doing something caused a certain event (the Bismarck's sinking). But what did she do? The officer launched a torpedo; that is what caused the Bismarck's sinking. Yet here again an agent's doing something (the officer launched a torpedo) can be understood as her causing something to happen (the officer caused the torpedo's launching), where this is to be understood in terms of a relation between her doing something and some separable upshot (the torpedo's launching). But what did she do? The officer pushed a button; that is what caused the torpedo's launching. Let's say the following: where an action (X did A) can be analyzed in terms of a causal connection between another action and some external result (X did B and that caused $\mathrm{E}$ to happen), $\mathrm{X}$ did A causally-depends on $\mathrm{X}$ did B. And so, in our maritime narrative above, sinking the Bismarck causally-depends on launching the torpedo, and launching the torpedo causally-depends on pushing the button. Let's suppose that this last is not causally-dependent on some further action. In any case, the regress argument only insists that there must be some limit to the chain of causal-dependencies: where action causally-depends on action, there must be action 
that does not.17

The threat the regress poses is not simply that if performing an action would require performing infinitely many actions none would be possible. Here's an analogy. One mode of acquiring private property is by gift. ("It's mine because you gave it to me.") Since this involves objects that are already someone's property, there can be chains of acquisition by gift. ("It was yours to give because it had been given to you by so-and-so, and it was so-and-so's because ....") Such chains cannot go on forever, not because this would involve too many acts of giving, but because the intelligibility of any single act depends on another mode of acquisition-it is an essentially derivative ground of ownership. The spirit of our regress of causes is similar. In causally-dependent action we have an essentially derivative form of an agent's owning (up to) what happens, an essentially derivative form of crediting a person with that.

It can seem like a merely technical point to say that with causally-dependent action X's causing is just a matter of X's action's causing, but here the remoteness of the agent from what happens really is quite vivid. The subjects of causally derivative action, like the domino artist and the poor souls inhabiting Rube Goldberg's cartoons, exploit causal chains spooling out from more immediate interventions in the world as a way of realizing their aims. Once our naval officer has, say, pushed the button, the causal chain unfolds according to its own principles. The subsequent accumulation of things she can be said to have done (launching the torpedo, sinking the Bismarck) does not involve any further contribution or effort. She could just as well be dead as the causal order of events marches along, now under its own steam, toward the external result (the torpedo's launching, the Bismarck's sinking).18 Such things are "up to nature," but there must be something else, something up to me, at the origin of any domino cascade if what subsequently happens can be put down to me, even if only by courtesy.

Now, someone may want to exercise the prerogative of terminology and insist that we call "basic action" whatever limits a series of causal-dependencies. This is fine. What matters for our purposes is only whether the regress argument establishes that there must be basic action in our specifically teleological sense. The crucial question is whether the following is true: If X $\operatorname{did} A$ is a limit to a series of causal-dependencies (i.e. cannot be analyzed as $\mathrm{X} \operatorname{did} \mathrm{A}$ * and that caused $E$ to happen), then there is no $A *$ such that $X \operatorname{did} A *$ in order to do A. It does not. 
Return to our highly circumscribed adventure at sea: the officer pushed the button and that caused the torpedo's launching and the Bismarck's sinking; and thus she launched the torpedo and sank the Bismarck. Now, it does not unsettle the supposition that pushing the button is causally independent when we add that the officer took some preparatory steps, say, that she broke the glass seal in order to push the button. Consider some further variations: The officer pressed the button for 30 seconds and that caused ... ; The officer pressed the button three times and that caused ... ; The officer pressed three buttons sequentially and that caused, and so on. Let's suppose pushing the button (for 30 seconds, three times, ... and then that button and finally that other one) involved the deployment of means: she pressed (for 15 seconds . . . , the first time ... , the first button ... ) in order to realize the relevant whole. It is plain that we are not thereby in a position to analyze, say, her act of pushing three buttons in terms of a causal relation between her pushing the first one and its result. The presence of teleological structure does not deprive the respective acts of button pushing of being what brings a series of causally-dependent actions to an end and of being what sets the relevant chain of events in motion. The regress of causes does not force us to basic action.19

\section{The limits of practical cognition}

I would like to turn to another sort of regress argument, one which grows out of reflection on practical cognition. The rough idea is that some things are done on the basis of thought about how to do them, but these must come to a limit in something an agent "just does," where this means: does without such thought. Of course, whether the regress establishes a limit on the application of means-end reason, and the relevant sort of dependence of one action on another, will depend on what it is to do something on the basis of thought about how to do it. I consider a few interpretations.

Deliberation must come to an end. How am I going to get that down from there? (My hat is stuck in a tree.) The search for an answer is the search for means. I figure, calculate, and deliberate. I work it out: I can get my hat by moving that crate over here, climbing up on it, and then hooking the hat with this stick. But I don't know how to move that huge crate. I deliberate and work it out: I can do it by doing such-and-such. But then I wonder how to do such-and-such. We are off on the regress. Deliberation, as Aristotle says, works its way towards things one can do without having to calculate out its phases. Indeed, he thinks, deliberation must come to such a limit if 
there is to be any action at all. The problem is that "if a person deliberates at every point, he will go on for ever." 20 Action will never break out.

The viciousness of the regress is sometimes understood along the following lines. Figuring out how to do something takes time. And so, if deliberation did not come to an end, the performance of any action would involve the performance of an infinite number of temporally extended actions, but this is absurd: too many actions would be required to do anything at all.21 There is another, and, I think, better way to characterize the threat of the deliberative regress. Engaging in certain activities presupposes that one takes oneself to lack knowledge of a certain kind. Searching for something presupposes an unresolved where-question: I do not know where it is; moreover, I know that I don't. Deliberating about how to do something presupposes an unresolved how-question: I do not know how to do it; moreover, I know that I don't. To suppose, then, that deliberation does not come to an end is simply to suppose that the (self-conscious) lack of knowledge how never comes to an end. It is to suppose that an agent is always confronted with an unresolved question "How to do A?" Now, roughly speaking, if X is doing A intentionally, then X knows how to do A (at the very least, $\mathrm{X}$ does not think she lacks such knowledge).

22 If so, then to suppose that deliberation never comes to an end is to suppose that a condition of acting intentionally cannot be met. On this understanding of the regress, deliberation must come to an end because one cannot act in a state of (self-conscious) ignorance, and not because action would otherwise require the performance of an infinite number of actions. In any case, I want to accept the result: there must be action which is not preceded or accompanied by conscious calculation, if there is to be any action at all.

Someone may want to exercise the prerogative of terminology and insist that an action performed without first calculating out how to do it be called "basic action." This is fine. What matters for our purposes is only whether the regress of deliberation establishes that there must be elementary operations in our specifically teleological sense. The crucial question is whether it is a condition of acting intentionally and for the sake of an end that an agent consciously entertain or reflect on a thought linking action and further objective in some conscious act of calculation. But there is no such condition. One can intentionally do A in order to do B even though one does not consciously reflect on the connection between A-ing and B-ing at any moment, either before or during the action. When thinking about the operation of means-end reason and the applicability of teleological explanation, 
what interests us is not what crosses the mind (of course, yes, there must be a limit to this) but, as Anscombe puts it, "an order that is there"-whose existence is constituted by various instrumental-rational connections that the agent presupposes, and which he presumably could articulate for himself if he reflected.

Many think, as Aristotle himself seems to think, that precisely where there is techn'e-skill, craft, technique, competence-there is no deliberation. One comes to the scene of action in possession of a kind of cognition that eliminates the need, or even room, for further inquiry. In Aristotle's classification of intellectual excellences, techn ${ }^{-} e$, like the other basic types of cognition, is a habitual state (hexis) — something that one has even when asleep and that might be exercised on any number of occasions. But, unlike the others, it is productive - the exercise of such knowledge is exhibited in individual action (poi-esis) undertaken in particular circumstances.23 And, indeed, the crucial point for our purposes is that the course of a skillfully performed action is not mediated by conscious calculation. Instead, one's skill has immediate application to the circumstances at hand-one acts straightaway. Nevertheless, phases of even the most skillful, unreflective, and routine action can be bound together by instrumental rationalization. This is plain where the skill is complex, an intelligible unity of other skills, as house building is of foundation laying, framing, roofing etc., or pastry baking or ship building are of the relevant subordinate capacities. And when a complex skill is exercised, these relations of dependence are reflected in the means-end structure of the particular action, as when I who, having received the Meilleur Ouvrier de France $\mathrm{P}^{\wedge}$ atisserie, know what's up with baking a cake, am making the batter by beating this butter and sugar in order to bake one for the party tomorrow.

Although an argument that there must be skillful action does not take us to basic action in our sense-complex skill interferes - it does suggest another route. Namely this: to argue that if there are complex skills there must be simple ones. And perhaps it is in these that we encounter the necessity of basic action? I want to investigate this possibility, though only after it has been recast in terms of a distinction, familiar from Jennifer Hornsby, between kinds of knowledge how to do something.

Procedural knowledge must come to an end. The house builder builds houses, and so knows how to do this. We ask, "How do you build a house?" Our builder answers, "By laying a foundation, then framing the walls, and then ...." The answer describes the way he does this, his method or procedure. 
This description of how he builds a house is a further specification of what he does: "I build a house by laying a foundation, framing the walls, and then ...." And in describing the procedure he expresses knowledge how to build a house. Following Hornsby, let's say that knowledge how to $\varphi$ is procedural knowledge when it can be expressed in the form I $\varphi$ by $\psi$-ing. Our how-question seeks the articulation of relations of dependence among subordinate phases of something one does. Although an answer to it might be suitable material for a lecture on the relevant topic, procedural knowledge is essentially exhibited in action, not in outward description or inward contemplation. Its fundamental deployment is in doing what one knows how to do. Procedural knowledge is productive knowledge. In doing what one knows how to do, a subject manifests knowledge which can be exercised on any number of occasions, and so be manifested in any number of individual actions of the relevant type. Procedural knowledge is general knowledge.

A statement of the form I $\varphi$ by $\Psi$-ing does not express knowledge how to $\varphi$ unless the subject knows how to $\Psi$. Our house builder's knowledge of subordinate operations_-laying a foundation, framing walls, roofing and so on-also can be procedural. We press our inquiry, "How do you lay the foundation?" He says, "I dig a hole and fill it with concrete." "And how do you ... ?" The question arises whether there is a limit to an agent's procedural knowledge, and thus a limit to the things one does by means of doing others. Experience seems to present plenty of examples of someone who knows how to $\varphi$, but who does not know anything of the form I $\varphi$ by $\psi$-ing. The bodily activity of walking is paradigmatic, Hornsby says. Typically someone who knows how to walk cannot speak to the question "How do you walk?", and does not know anything that can be expressed as an instance of I walk by - -ing. This is so in my own case. Even if I were to consult a physiology textbook, learning something of the underlying mechanics of walking, such knowledge would not be of the means by which I walk. Although particular walks would accord with my new found physiological knowledge, they would not be from it: such knowledge would not enter into their account. In contrast, my knowledge how to walk, like our builder's knowledge how to build a house, is productive and general: what was exercised in yesterday's walk might be exercised in any number of acts of walking. Following Hornsby, let's say that when such knowledge cannot be expressed in the form I $\phi$ by $\Psi$-ing it is practical knowledge. 
Hornsby does not rest with the observation that there is, in fact, practical knowledge. Rather, she argues that there must be such knowledge:

"Among the things a person knows how to do, some of them he must know how to do 'just like that', on pain of needing to ascribe to him indefinitely many distinct pieces of knowledge to account for his ability";24

"Some things — at the end of these 'by'-chains, as it were-must be done without possession of knowledge of procedures. These are things an agent does 'directly'. They are basic things, in one sense of that action-theoretic notion. They are things which we are inclined to say the agent is able to simply do." 25 As before, concern about a regress carves a space for basic action. Hornsby's thought is this: were procedural knowledge the only mode of knowing how to do something, it could not reach all the way out to action. It would not be productive. So there must be practical knowledge: this is the ultimate source of rational efficacy, providing "for our doing all of the things and engaging in all of the activities which we do or engage in as agents." 26 And since the object of practical knowledge just is basic action, there must be basic action if anyone is to do anything at all.

Where does this leave us? When someone's knowledge how to do something is not procedural knowledge (is not knowledge how to do such a thing by doing other things), it is practical knowledge, and what one knows how to do is a basic action. It is crucial to emphasize that what one knows, the object of practical knowledge, is a type or form of action. A basic action, in the sense at issue in this argument, is an action-type cognized in a certain way. It thus has the generality characteristic of such cognition. But now recall that our own inquiry has been about the constitution of individual actions or performances, "events in a man's history," as Anscombe says. Must there be an inner limit of the means-end order in the doing of any deed? Anscombe's questions "why?" and "how?" are devices for eliciting a description of the phases of individual action. They ask why and how someone is doing or did something, in contrast to the how-question ("How do you build a house?") that brought our house builder to express knowledge of how, in general, to build a house, of how he does something. There is, then, a gap between Hornsby's thesis that there must be basic actions (concepts) — teleologically unstructured conceptions of types of things to do-and any answer to our question whether there must be basic actions (deeds) - teleologically unstructured doings of things.

Although Hornsby's official description of practical knowledge and basic 
action are given in terms of what stops an otherwise vicious regress, we should not underestimate the role examples play in putting us in touch with the relevant ideas. In addition to bodily activities like walking and swimming, Hornsby and others mention pure bodily movements like raising an arm, bending a finger, and clenching a fist, as well as such things as riding a bicycle, typing, playing a musical instrument and turning left on skis which involve objects beyond the limits of the body. A feature of all of these examples is the absence of reference to particulars: Hornsby's basic actions do not make mention of names and places, this or that, here and now.

The decisive question is whether the individual actions in which an agent exercises practical knowledge must themselves lack the structure of means-end rationality.27 This question is not settled by the observation that there are generic action-types an agent knows how to perform, where this knowledge does not rest on knowledge how to perform other generic action-types. For it might be that I do not know any general procedure for walking, but that nevertheless, when I walk on particular occasions, I perform these actions by knowingly taking certain particular means. I want to argue that practical knowledge can be exercised in particular actions structured by means-end reason. Indeed, my own view is that it must be. When we are seduced by the simple argument above, what goes out of view is that general knowledge of how to do things is applied in a way that takes account of determinate particular circumstances. (It would be interesting to say how this could get out of view so easily.) Suppose I exercise my knowledge how to walk in walking from this rock here to that tree over there. I can know that I have intentionally walked to this point here which is about half-way in order to walk to that tree; or again, I can know that part of the way I walked to the tree was by walking to this point. And I can know these things in virtue of intentionally bringing them about. We might call these items of knowledge "knowledge of particular means." They are means because they are (arguably) things I do in order to complete my larger project. They are particular because in characterizing them I do not mention any other generic act-type except walking, but nevertheless their characterization involves mention of more than simply a generic act-type. It involves specifying how, in the circumstances at hand, a particular action of that type is constituted from its lesser parts. And it is not clear why there must be a limit to such specification. Do I not intentionally walk from here to there by intentionally walking every inch of the way? 
I am attracted to the thought that any performance manifesting practical knowledge must involve drawing on knowledge of particular means in the course of realizing an end. This means-end order is not contained in the action concept itself, but in material circumstances in which such a concept is exercised. When one exercises practical knowledge on a particular occasion and thus in particular circumstances, one's end is not simply the generic end of, say, walking, grasping, or turning left on skis, but something with a specific telos such as turning left along this path (or through those trees, or before I hit that! etc.) grasping this cup, or walking from here to there.28 When making a left turn skiing, one does not simply go left in an indivisible instant and one does not merely make generic leftward movement. One has to, and, knows one has to, turn left somewhere and somehow_turning left is not something that can be realized simply per se. Making the turn takes time and essentially involves a course of leftward movement: one is already moving downhill and faced with an array of possible trajectories, some more or less steep, more or less dangerous, and when turning left one charts a course leftward, as it were, ordering one's movement in a certain definite way. Similar points might be made about other generic act-types, like walking, grasping, riding a bicycle and so on.

Finite agents must implement practical knowledge in particular circumstances, the particularity of which is known to the agent. We act self-consciously on other objects (not just other kinds but other ones) and in space and time (not in 1 and at $\mathrm{t}$, but here and now). These are continuous magnitudes. And a subject who moves self-consciously through space, or does things that take time, grasps this at least intuitively. If I know that I am walking to school, then I know that I need to traverse the entire, continuous distance from where I am now to school. I understand the idea of going halfway there, and halfway to halfway there, and so on. And this sort of understanding supplies a basis for the unlimitedness of rational teleology. Perhaps, in every case, there is some most basic generic type of description of what I am doing: maybe "walking" or "grasping" is on an occasion the most basic of the generic types of action I undertake. Nevertheless, this action concept will be determined, in any given case, by other objects as well as various spatial and/or temporal detail. When I am walking, I am walking from somewhere to somewhere, and in doing this intentionally I act from a grasp of what to do in order to get from here to there. This is the structure of skillful, concept realization by finite rational beings. Why not?29 
The preceding sketches an idea about how we might think of the inner structure of particular actions. I have tried to make this proposal plausible by considering its application to a few simple cases. That is obviously only a weak form of argument. But whatever one thinks of this positive proposal, the crucial lesson of this section is that the various regress arguments do not establish that there must be basic action. In the final section I will give a more principled reason for skepticism about whether there can be such a thing.

\section{Can There be Basic Action?}

It is said that when "X $\operatorname{did} A$ " reports an action, someone's having done something intentionally, the subject herself is the source and guide of what has happened; she has brought it about, not unwittingly, but knowingly in execution of an aim. I take this mixture of familiar metaphors to express ideas that are widespread, and that do not belong to some particular theory of what it is to act, but to the characterization of the phenomenon of which a theory is wanted. The question is whether basic action is adequate to them.

\section{"A state of externalization, of alienation"}

In rationally purposeful activity, what is at first only an abstractly envisaged end, a glimmer in the eye, something aimed at but not yet there-maybe I've got it in me to build a sandcastle-develops over time, acquiring concrete determinacy as things move along: details are filled in and hammered out, flesh is put on the bones, reality accumulates, until finally the job is done and the process complete. Success! I did it: I built a sandcastle. The execution of a project such as this is making a transition from incomplete to complete, from doing to did. It is equally a transition from general representation to concrete particular: only when I have built a sandcastle can we refer to my act of building a sandcastle, and this act, like the sandcastle itself, is a fully determinate, concrete particular, something for which I am responsiblemaybe I've signed or put my stamp on this thing-but that is nevertheless now all on its own in the world. The moment of completion is a sort of letting go. What fills the gap between incomplete and complete, or general and particular, is the progress of the deed, the getting done of what gets done. My thought is this: a subject of basic action would be alienated from the progress, or getting done, of his deeds, much as Marx understands the 
non-worker (Nichtarbeiter) to be alienated from the material processes that realize his own ends and fortunes. Imagine the non-worker watching the price of his stock rise as the workers on the factory floor churn out widgets: "Now I'm really making widgets! Now I'm making some real money!" The nonworker lives off the work of others. Marx calls him a parasite and suggests that in an important sense he lacks autonomy — not because his ultimate ends are merely given to him by something else, but because he does not realize what ends he has, however he comes to have them, through his own activity. Unlike a parasite such as the whale louse, a crab-like creature found on the skin of marine mammals, which knows nothing of the work done by its host, Marx's non-worker might have awareness of the material processes that bring actuality to his ends, "the real, practical behavior of the worker in production."30 Yet such awareness would be of something alien, outside and external, something given through observation-a matter of being put into contact with what is already there.

Of course, there is nothing especially disquieting about getting some help once in a while: sometimes the way to do something just is to get someone to do it for you. In such a case, as one's agent operates on one's behalf, one is brought closer and closer to the realization of one's end-destroying a rival, perhaps—without willing or even knowing about what constitutes such progress: "I don't want to know how, Scooter. Just take care of it." Yet orders cannot be passed down without end: "Someone's gotta get his hands dirty." And there would be something especially disquieting about a description of our own agency that put us at a similar distance from all the real work, or dirty work, as the case may be, fuelling the progress of the deed.

The central worry about basic action, then, is that it puts the agent in fundamentally the same sort of relation to whatever constitutes such progress as Marx's non-worker is in to the labor process that constitutes the transformation of his idea into reality. The underlying sources of change are vastly different: it is other human beings who do the work, on the one hand, while on the other, the job is metaphysically outsourced to a sub-personal workforce.31 Still, in each case, the process of doing something intentionally turns out to be a case of delegating tasks to another power. In each case, how the process comes to completion is not willed, and at best watched: the causal work is not the agent's work, his knowledge not self-knowledge. 


\section{The temporality of action}

I want to attempt a plainer, less imagistic attack on the idea of basic action.

It proceeds simply by describing what such a thing is, an admittedly odd, because seemingly too straightforward, strategy. Nevertheless, I suspect certain features of philosophical practice and writing - in particular, the tremendous reliance on abstract noun phrases ("action”, “event”) and name-like phrases ("X's doing A to Y", "Y's A-ing") in the formulation of general philosophical theses - conceal the bad fit with most any pretheoretical characterization of the phenomenon of which a theory is wanted. To get the strangeness of basic action in view we must have the temporal structure of action properly in view, and for this we must return to the grassroots representation of action in complete sentences or thoughts.

Consider the following:

- I was walking across the street.

- I walked across the street.

The subject (first person), predicate (walk across the street) and tense (past) are common elements of these thoughts. And yet they are not the same: that I was walking across the street does not entail that I walked across the street. They differ in aspect. What the proposition with imperfective aspect (I was walking across the street) represents as in-progress and underway, the correlated proposition with perfective aspect (I walked across the street) represents as finished and done. The aspectual distinction is a distinction among ways in which subject and predicate can be joined to form a complete thought. In this case, where the predicate is walk to school, there is not merely a distinction but an opposition between these two modes of predication.

To see this we must introduce a further imperfective thought, one reporting that things are presently underway: - I am walking across the street.

The aspectual opposition is displayed in this: (i) If I am walking across the street, I have not yet walked there; (ii) If I walked across the street, I am no longer walking across the street.32 When walking across the street is underway, it is not complete; when it is complete, it is underway no more. In any one moment, perfective and imperfective aspect (like being and not-being, affirmation and denial) shut each other out. And yet (unlike being and not-being, affirmation and denial) the poles of the aspectual opposition are not simply at odds. Here doing looks forward to having done: when walking across the street is in progress, it is not then finished, but nevertheless it 
reaches ahead to completion.

A present tense judgment such as I am your killer is vulnerable to falsification by the actual future (my gun is empty, yours is not), and, in that, unlike I am walking across the street, which does not incorporate what will actually come to pass into the description of current events. That I am walking across the street does not entail that I will ever make it (collision with a bus midpoint, alien abduction, change of mind). But if being in progress is compatible with never finishing, in what sense does I am walking across the street involve the description of the here and now in the light of completion? Consider this: I am walking across the street, and then later I am not walking across. What happened? There are two possibilities: either I made it (and thus could not still be walking across), or else I did not make it (bus accident). We have here a distinction between finishing and merely stopping, being completed and being left incomplete. But such a distinction is not always available where a proposition is true for a while and then false (e.g., I am $75 \mathrm{~kg}$, and then later I am not $75 \mathrm{~kg}$ ). Still, there is more to looking forward to completion than looking forward to a time at which either I did or I did not bring things to completion. Finishing and merely stopping are not on a par. The concept deployed in the imperfective judgment (walk across the street) specifies a terminus or limit, a point beyond which progressive truth cannot continue, and only this stopping point is internal to the description of the proceedings. That I am walking across the street has intrinsic direction; it is a specification of what is to be, even if not what will be in fact. When I do not make it (bus accident etc.), we say that things were interrupted and cut off, something interfered and got in the way. These expressions, like progressive truth itself, presuppose the presence of a real tendency toward (and not just idle hope of) eventual completion.33

Of course, the aspectual opposition (as well as the corresponding metaphysical contrast between things underway and things brought to completion) has nothing especially to do with walking across the street, or, quite generally, with concepts deployed in action. The predicative material in any of the following progress reports generates our opposition: The sun is setting; The cherry tree is blooming; The robin is flying to its nest; Jones is baking a cake. Indeed, I have been drawing on a tradition reaching back to Aristotle whose abstract category of kin ${ }^{-}$esis (movement) is specified in aspectual terms: very roughly, where a predicate is such as to generate our aspectual opposition it expresses a kin`esis.34 $\mathrm{A}$ kin $^{-}$esis concept is what figures in propositions 
of our three abstract forms ( $\mathrm{X}$ is doing $\mathrm{A}, \mathrm{X}$ was doing $\mathrm{A}, \mathrm{X} \operatorname{did} \mathrm{A}$ ) where these have the following inferential relations: If $X$ is doing $A, X$ has not yet done A; If X did A, X is no longer doing A. The concepts deployed in action, concepts of things to do, are such concepts, and the temporal structure of action is that of kin"esis.35

Thus far I have said that action, indeed, kinesis (movement) quite generally, is either complete or incomplete. Moreover, when one is incomplete, it is incomplete by degree ( $\mathrm{X}$ is just getting going, about half-way done, almost there). This is a presupposition of the thought that a kin ${ }^{-}$esis is quick, slow or some speed: when something is underway there is a rate at which it is approaching completion.36 In the typical case, as X is doing A through an interval, less and less still needs to be done. Things are coming along. But what exactly does such progress consist in? It consists in a connection to other events, themselves at various stages of completion. The idea is again Aristotle's: "In their parts and during the time they occupy, all movements are incomplete, and are different in kind from the whole movement and from each other." 37 When something has begun, is in progress and not yet complete, when $\mathrm{X}$ is doing $\mathrm{A}$, something else has already been done and other things are underway. Indeed, it will be possible to link the process ascription "X is doing A" with these others by saying "in that" and then mentioning other things that have already happened (a minute ago it $\operatorname{did} A * *$ ), and further things that are happening (at the moment it's doing A*).38 As before, this is a general phenomenon that we find wherever we have events and processes: - The house is burning down: the kitchen burned down, the attic is now burning. - The cat is stalking a bird: the cat crouched down, the cat is now slinking along. - I am baking a cake: I made the frosting and now I'm mixing flour and sugar. - I am walking from Athens to Delphi: I walked from Athens to Thebes, now I'm walking from Thebes to Delphi.

The happenings here represented as phases, stages, or parts of an event, might in other circumstances be a mere heap. Not just any collection or succession of events is a unity: walking from Athens to Thebes and walking from Thebes to Delphi would not add up a single event of walking from Athens to Delphi were I to get the idea of walking to Delphi only after I was already in Thebes. Progressive truth (in this case that I am walking from Athens to Delphi) must hang overhead throughout: it is the principle of unity of a single event. 


\section{What happens when someone performs a basic action?}

Against the background of this picture of the temporality of movement (kin ${ }^{-}$esis) and so specifically intentional movement or action, I now want to describe what a basic action would be. It would be a mistake to run together the following attempt at illuminating description in light of this temporal structure with an attempt to prove the impossibility of basic action on the basis of it.39 My thought is simply that when described in light of this temporal structure basic action will not be recognizable as action.

Suppose $\mathrm{X}$ did $\mathrm{A}$ and that this is a basic action. It follows from the temporal structure of processes that earlier $\mathrm{X}$ was doing A and had not yet done it. Consider the time, then, when $\mathrm{X}$ is doing $\mathrm{A}$. It follows, again from the temporality of processes, that other things have already happened ( $\mathrm{X} \operatorname{did} \mathrm{A} * *$ ), and still others are underway ( $\mathrm{X}$ is doing $\mathrm{A} *$ ). Indeed, these subordinate phases have the same temporal structure. And so, earlier when $\mathrm{X}$ was doing $\mathrm{A} * *$ and had not yet done it, other things had already happened $(\mathrm{X} \operatorname{did} \mathrm{A} * * *$ ) and still others were underway ( $\mathrm{X}$ was doing $\mathrm{A} * * * *)$. The action in progress ( $\mathrm{X}$ is doing $\mathrm{A}$ ) is at once an ever increasing stack of have done's and ever shrinking list of still to do's. When all goes well, the accumulation of subordinate have done's constitutes the completed action (X did A): the subject's aim of A-ing is materialized in them. 40

We are supposing that doing $\mathrm{A}$ is acting. And so, we are supposing that, unlike when the sun is setting or when the tree is falling down, here doing $A$ comes from the subject in execution of an aim; the subject is not undergoing but bringing about the process, as agent in pursuit of a goal. Moreover, we are supposing that, unlike the cat who is stalking a bird or the bird who is flying to its nest-both subjects of goal-directed processes-our subject, who is doing A intentionally, represents herself through the concept A, not simply as something falling under a concept (as she would were she to think that she is falling down) but as realizing the concept. In the fundamental case, $\mathrm{X}$ is not doing A intentionally if she does not know that she herself is doing A, or even if she knows this but only on the basis of observation or inference. As the agent, she has a special sort of knowledge of what she is doing when she is doing it intentionally: it is knowledge "without observation," as Anscombe puts it, a sort of self-knowledge, indeed a specifically productive form of this.

Now, since doing $A$ is basic it follows that, at any point during the proceedings, what $\mathrm{X}$ has already done $(\mathrm{A} * * *, \mathrm{~A} * * * *)$, and what else $\mathrm{X}$ is doing $(\mathrm{A} *$, $\mathrm{A} * *)$, do not involve anything that is per se an intentional action. By hypothesis, 
the subordinate phases of a basic action are not themselves undertaken in pursuit of the goal. (Indeed, it would seem that were X interrupted, X would not have intentionally done anything at all. For whatever $\mathrm{X}$ had already done would not amount to having done A, but would be only a phase of that.) Moreover, if all goes well, nothing that figures in the constitution of the whole completed action, none of the phases or proper parts of X's having done $\mathrm{A}$, will be per se intentional actions. The progress of the deed toward its completion is thus wholly opaque to its subject, except in the way it might be known to an observer or to someone with general knowledge of how such things happen. In short, the subject of basic action is alienated from the progress of her deed.

Earlier we encountered the idea that someone's action might be ongoing when she is asleep or even, as Davidson suggests, dead. This is the causally-dependent, or posthumous agency of our naval officer who, already having launched the torpedo, is sinking the Bismarck. The subject of basic action is in more or less the same situation with respect to the progress of her deed. The agency exhibited in a basic action is like the agency exhibited in a causally-dependent action with this crucial difference: the period when nature is taking its course occupies a different position in the unfolding story of the deed. It comes at the beginning, in the first and fundamental step, and not later as one waits for the ship to sink, king to die or last domino to fall. It looks like performing a basic action is just being the subject of a mindless, automatic process which the subject has somehow initiated, triggered, or launched. (It would be possible to raise a question about what such initiating or triggering could come to, but I will not take up that matter here.) It seems the I am doing A of basic action is like the I am going to the moon of someone strapped to a rocket labeled "to the moon" who has already (somehow) launched the rocket. But, whereas in the case of causally-dependent agency, we admitted this as an action precisely because we could regard it as a derivative and parasitic case, inheriting its credentials from indubitable cases of living, self-governed intentional operation, here the alienation infects the basic and fundamental case, that in virtue of which anything else is said to be a manifestation of agency at all.

When no phase of a process comes knowingly from the subject for the sake of the end, what can be the basis for thinking that the process itself, the accumulation of such phases, is rationally goal-directed? How, that is, could "basic action" qualify as action in the intuitive sense for which we all 
want to account, as something the subject brings about, not unwittingly, but knowingly in execution of an aim? Heard one way, the following are merely reformulations of what defenders of basic action hold to be possible: "I am doing A, but I know nothing of how this is getting done" and "I did A, but I did not do what was necessary to carry it out." Heard another way, I hope they will sound paradoxical, as though the second clause denies the very thing the first asserts. If the latter impression is sound, then "basic action" seems not to be action at all.

\section{"The labor of superintendence"}

The capacity to perform a basic action "boils down to a capacity rational agents have of getting [something] done without needing to cognitively control how it is done." 41 The passage is from Berent Enc $s$, who is admirably clear-sighted about the need for this sort of commitment. To Enc it seems "intuitively clear" that we have this capacity. To me it seems intuitively clear that we do not have an intelligible conception of rational agency, if we just have something that announces the thing to do, leaving the execution of the task to another power. Reason is not practical (i.e. efficacious) if it is simply agenda setting in this way: it must also be sufficient to the realization of its ends, and thus must be able to constitute the progress of the deed, the getting done of what gets done. 42

Others will want to challenge my characterization of what happens when someone performs a basic action. We can imagine the basic action theorist responding to the accusation of alienation much as Marx imagines the capitalist answering the charge of idleness: "'Have I myself not worked? Have I not performed the labour of superintendence, of overseeing the spinner? And does not this labour, too, create value?" 43 The subject of a basic action does not merely initiate a material process, as I have suggested, but also, and crucially, sustains and guides it toward completion: "In the case of basic action, the crucial concept is that of guidance: when an agent A's intentionally, he wants to $\mathrm{A}$, and this desire not only causes but continues to guide behavior towards its object." 44 I cannot respond to this suggestion in detail here. Still, as a first step, I would want to ask what the guidance of a basic action could be, and what role there is, if any, for awareness of the progress of the deed.45

For the sake of argument, let's grant that basic action may be guided without awareness of such progress, and thus without awareness of the very things in which the progress resides, of what else has already happened and 
what else is underway. If the course of a basic action is guided or purposive, then the subordinate phases are not merely joined by blind mechanism, like the sub-movements of a tree's falling to the ground, but are elements of a teleological structure - each for the sake of the end. Yet, although the agent has set it in motion, this purposive accumulation of subordinate phases is nevertheless beyond her comprehension. The progress of the deed is nothing to her: it has teleological structure in the way that, say, the organic processes of digestion do. But if these phases and their connections are not for the agent neither is the process as a whole guided by her: where the agent does not know of the evolution of the process, she cannot impute it to herself, and where she cannot we cannot.

Maybe this is too quick? Many will rightly say that "we are generally unaware of many portions of the causal process - the activation of efferent motor neurons, the contractions of certain muscles-implicated in the production of our intentional overt actions." 46 And on this basis, some will question whether lack of this awareness undermines the idea that the deed's unfolding constitutes an exercise of agency. But we have to be careful here. It is one thing to be unaware of something "implicated in the production" of an action; it is another to be unaware of everything going into this. On our present supposition, the (putative) agent of a basic action lacks awareness not only of, say, underlying physiological processes (muscle contractions, neuron firings), but also of the intrinsic articulation in the development from doing to did. In thinking of something as, say, moving from one place to another, we are already thinking of it as having moved along some sub-path and as in the process of moving along others. An action concept of the form move from _ to _ contains a partial specification of that through which such a thing progresses toward completion, namely processes themselves of the form move from _ to _ _. And the difficulty is with the thought that the agent guides (controls, determines, directs, constitutes) the course of action without awareness of anything constituting its intrinsic articulation. But how might things look were basic action guided with awareness of the progress of the deed? Here is Joseph Raz:

"The element of guidance can be understood by analogy to a negative feedback mechanism: we, automatically and normally without being conscious of the fact, monitor the performance of the intentional action such that if it deviates from the course we implicitly take to lead to its successful completion we correct the performance, bringing it back to the correct path, or interrupt it, when we fail 
to correct it."47

There are two difficulties facing any attempt to supplement our initial story of the progress of a basic action with such a conception of guidance. The first is about the very possibility of a subject of basic action monitoring its progress. Because there are typically many, many ways of realizing an end (think of skinning a cat or all the roads to Rome), and because the subject of a basic action does not know which specific path things are to take, it does not seem that the subject of a supposed basic action could be in a position to know that things are going badly until it is too late-that is, until something has happened that is flatly incompatible with completion. 48

Even if we bracket this doubt and suppose that the subject is in a position to monitor the proceedings, intervening when necessary, his awareness of these proceedings would be by observation. All that goes to constitute his intentional progress - what else he is (in some sense) doing - appears to him, like the work on Marx's shop floor, as "theoretical behavior." And here I cannot do more than echo the tradition on which "the essence of passivity with respect to an event is witnessing it" and the essence of activity, and specifically, productive activity, is knowing an unfolding process in some other way.49 Whatever knowledge an agent might have of the progress of a basic action it would not be self-knowledge, specifically that form of it Anscombe calls practical knowledge-the cause, not the effect of what it understands.

We can now turn Danto's original intuition - that a complex action is composed of parts that are themselves actions_-on its head. If intentional actions must be composed fundamentally of basic actions, and if what is going on during a basic action is something that is happening automatically (albeit perhaps as the result of a process somehow launched and monitored by the agent), then it looks as if every intentional action is composed fundamentally of phases in which the agent is not intentionally doing anything at all, only, as we might put it, waiting hopefully (or perhaps with well grounded expectation) for something to be done. So, if a complex action must be composed of parts that are themselves actions, and if putatively basic actions are not actions at all, then complex actions cannot be composed out of such elements. Basic action is not action at all and has no place in an account of this topic. 
Notes

$\star$ I first presented a version of this paper at the Hester Conference on Action and Agency at Wake Forest where I benefited greatly from Joseph Raz's commentary. I have subsequently accumulated many debts to many others who have been very generous and resourceful in their help. Thanks to audiences at Auburn University, Brandeis University, UC Berkeley, Dortmund University, University ofWisconsin-Milwaukee, Kansas State University, University of Chicago, Northwestern University, University of Toronto, the Pittsburgh Area Philosophy Colloquium and UCLA. And thanks also and especially to Matthew Boyle, Jeremy David Fix, Kim Frost, Matthias Haase, Eric Marcus, Richard Moran, Ram Neta, Sebastian R” odl, Guy Rohrbaugh, Gisela Striker, Michael Thompson and two anonymous referees for No^us.

1 Arthur Danto, “Basic Actions,” American Philosophical Quarterly 2 (1965): 141-148, at 147.

2 "We are, to complete this conceit, in the image of God so far as we have some basic actions ... available to us" (Arthur Danto, Analytical Philosophy of Action [Cambridge: Cambridge University Press, 1973], 35). It is certainly the position of classical theology that a divine agent does not put means to ends and so performs only basic actions. Consider Aquinas: he combines the thesis that the divine intellect is practical (ST 1.19.1), with the denial that God wills "this on account of that" (ST 1.19.5) or again that God acts "for the acquisition of some end" (ST 1.44.4). (St. Thomas Aquinas, Summa Theologiae, trans. Fathers of the English Dominican Province [London: Burns Oates, 1920; repr. Westminster, Md.: Christian Classics, 1981]). It might appear, then, that skepticism about basic action must bleed into skepticism about divine agency. But it does not in fact. Putting means to ends is a mode of operation suited for finite and limited beings, and thus incompatible with divine perfection. It is for this reason that Aquinas denies that God partakes in it. If we pause for a moment, we will see that many other central features of human agency are incompatible with divine perfection. Divine perfection is incompatible with having an unfulfilled end: the will of God is always fulfilled (ST 1.19.6), which is not to say that God eventually gets what he is after, but that here there is simply no conceivable gap between representation and reality. Divine perfection is equally Incompatible with undergoing change (ST 1.9.1): God is not an intelligible subject of judgments of the form $\mathrm{X}$ is $\mathrm{F}$ and then $\mathrm{X}$ is not $\mathrm{F}$. And divine perfection is also incompatible with being the subject of temporally extended processes or events (ST 1.10.2): God is not an intelligible subject of judgments of the form $\mathrm{X}$ is doing $\mathrm{A}, \mathrm{X}$ was doing $\mathrm{A}, \mathrm{X} \operatorname{did} \mathrm{A}$. Even so, I do not want to deny the intelligibility of the idea of divine agency. Nevertheless, whatever intelligibility it has, it has through other channels than giving application to the forms of predication at the ineliminable core of our own intentional operation. And, as I eventually argue (section 5), it is only where and because these forms of predication frame practical consciousness that there is a problem about basic action at all. 
3 Marx does not dwell on the alienated condition of the non-worker but his brief remarks are suggestive: "The first remark is that everything that appears in the case of the worker to be an activity of externalization, of alienation, appears in the case of the non-worker to be a state of externalization, of alienation. Secondly, the real, practical behavior of the worker in production towards his product (as a state of mind) appears in the case of the non-worker opposed to him as theoretical behavior." Karl Marx, "Alienated Labour," in Karl Marx: Selected Writings, ed. David McLellan (Oxford: Oxford University Press, 2000), 85-95, at 95. 4 I take the expression “teleological basicness” from Jennifer Hornsby's Actions (London: Routledge \& Kegan Paul, 1980), ch. 6. However, the content I assign to this expression is not Hornsby's concept of teleological basicness. The difference is roughly this: Hornsby's interest is in basic action concepts, the teleologically unstructured grasp of a type of thing to do, whereas I am interested in basic actions or performances, the teleologically unstructured doing of something. This distinction is developed in greater detail in section 4, where I consider the substantive question whether the exercise of a basic action concept (what Hornsby sometimes describes as the exercise of practical knowledge) must be a basic action, a basic deed, in the sense I describe here in section 2. I hope remarking on these terminological differences is enough to ease, or at least postpone, worries that I simply fail to register or aim to undermine other understandings of what basic action is, especially including the idea of an object of practical knowledge which is so central to Hornsby's work. (Also see her "Semantic Knowledge and Practical Knowledge," Supplement to the Proceedings of the Aristotelian Society 79 (2005): 107-130, and "Knowledge and Abilities in Action," in Cultures: Conflict-Analysis-Dialogue, Proceedings of the 29t International Wittgenstein Symposium, eds. C. Kanzian and E. Runggaldier (Ontos Verlag, 2007),165-80.)

5 As I hope is already clear, this essay is concerned specifically with intentional action, basic intentional action, intentionally doing $\mathrm{A}$ in order to do $\mathrm{B}$ and intentionally doing B by doing A, though I will usually simplify matters by speaking of action, basic action, doing $\mathrm{A}$ in order to do $\mathrm{B}$, and doing $\mathrm{B}$ by doing $\mathrm{A}$ simply. This is a terminological choice. It does not express a hyper-intellectualized conception of self-movement in general: in fact, I think it is crucial to a proper understanding of specifically intentional (selfconscious, concept realizing) action that it be seen as a species of self-movement. For further discussion see my "Goodness and Desire" (with Matthew Boyle) in Desire, Practical Reason and the Good, ed. S. Tenenbaum (New York: Oxford University Press, 2010), 161-201. To avoid misunderstanding let me add a further crucial remark about how I use the word "action" in what follows. There are various philosophical theories of the ontology implied in ordinary action sentences. Perhaps the best known and most widely accepted is the Davidsonian view, according to which an action sentence involves implicit existential quantification over events. Other analyses are certainly possible. (For a helpful overview see F. Pianesi and A. Varzi, 
"Events and Event Talk," in Speaking of Events, J. Higginbotham, F. Pianesi, and A. Varzi eds. [New York: Oxford University Press, 2000], 3-47.) My aim is to remain noncommittal about matters of ontology. When I speak of action I will mean simply whatever it is that is reported in a true action sentence. I assume that we have an intuitive grasp of the relevant class of sentences even in advance of having a proper account of their semantic structure and ontological commitments.

6 For the idea of a "facilitative reason" see Joseph Raz, "The Myth of Instrumental Rationality," Journal of Ethics and Social Philosophy, I.1 (2005): 2-28.

7 I am throughout, and especially here, greatly indebted to Michael Thompson's "Na“ive Action Theory," chapter 2 of his Life and Action (Cambridge, Mass.: Harvard University Press, 2008).

8 Ludwig Wittgenstein, Philosophical Investigations, 3rd ed. (New York: Macmillan, 1963), $\$ 621$. That Wittgenstein does not mean to launch a research program is, I think, plain from other remarks: "Willing, if it is not be a sort of wishing, must be the action itself. It cannot be allowed to stop anywhere short of the action.' If it is the action, then it is so in the ordinary sense of the word; so it is speaking, writing, walking, lifting a thing, imagining something. But it is also trying, attempting, making an effort,- - to speak, to write, to lift a thing, to imagine something etc.” (Philosophical Investigations \$615).

9 This thought too can seem as unproblematic as it seems inevitable. One's arm might rise, even if one does not raise it - maybe the wind raises it instead. And it can seem, as it does to John Searle, that "in such a case we have a bodily movement which may be exactly the same as the bodily movement in an intentional action" (Intentionality [Cambridge: Cambridge University Press, 1983) 89]). Whatever we say about the substantive question, it is a fallacy to reason that if being $\mathrm{G}$ is a necessary but not sufficient condition for being $\mathrm{F}$, there must be some nontrivial $\mathrm{H}$ such that together $\mathrm{G}$ and $\mathrm{H}$ constitute a necessary and sufficient condition for being F. For discussion which pays special attention to the analysis of action, see Anton Ford, "Action and Generality," in Essays on Anscombe's Intention, eds. A. Ford, J. Hornsby, F. Stoutland (Cambridge, Mass: Harvard University Press, 2011), ch. 2, and Robert Jaeger, “Action and Subtraction", Philosophical Review 82 (1973): 320-329.

10 Michael Smith, "The Structure of Orthonomy," in Agency and Action, eds. Hyman and Steward (Cambridge University Press, 2004), 165, my italics.

11 The expression "standard story of action" is taken from David Velleman, who, like Michael Bratman, Harry Frankfurt, John Searle, Kieran Setiya, and many others, takes the standard story of action as a starting point. See, for example, Velleman's "What Happens When Someone Acts?" and the "Introduction" in The Possibility of Practical Reason (Oxford: Oxford University Press, 2000); Michael Bratman's "Reflection, Planning and Temporally Extended Agency," Philosophical Review 109 (2000): 35-61; “Two Problems about Agency”, Proceedings 
of the Aristotelian Society, 101 (2001): 309-326; "Valuing and the Will” Philosophical Perspectives: Action and Freedom 14 (2000): 249-265; John Searle’s Intentionality and Kieran Setiya's “Explaining Action,” Philosophical Review, 112 (2004): 339-393.

12 John Bishop, “Agent-Causation,” Mind 92 (1983): 61-79, at 62. Further elaboration from Bishop: "The object of the agent-causal relation is not the action itself but rather certain events or sequences of events which, in virtue of their standing in this relation, count as intrinsic to the agent's intentional action. The events which are the object of an agent-causal relation - typically movements of the agent's body-will always bear some description which is logically independent of their standing in this relation" (ibid. 71). Of course, even those who hit action-theoretical bedrock in appeals to primitive and irreducible notions of volition, "act of will," or agent-causation aim at an elucidation of the general structure of action, the structure of what is represented in such ordinary thoughts as, say, that Jones raised his arm intentionally. The typical analysis is given in terms of a relation between an "active mental event" or an agent and what merely happens. And such views fall under the wide umbrella of the causal theory as I characterize it here.

13 See, for example, Maria Alvarez and John Hyman, "Agents and Their Actions," Philosophy 73 (1998): 219-245; Roderick Chisholm, "Freedom and Action," in Freedom and Determinism (New York: Random House, 1976); Carl Ginet, On Action (Cambridge: Cambridge University Press, 1990); Hugh McCann, "Volition and Basic Action," Philosophical Review 83 (1974): 451-73; Richard Taylor, Action and Purpose; (Englewood Cliffs: Prentice-Hall, 1966). 14 Donald Davidson, "The Logical Form of Action Sentences" in Essays on Actions and Events (Oxford: Oxford University Press, 1980) 121.

15 Kieran Setiya is very clear about the shape things begin to take on this way of thinking: "Suppose I am playing a particular piece of music. This is something I do by performing other actions, like playing a passage, or a movement of the piece, and finally by performing basic actions, like moving my hand in order to play a note .... What this comes to in the typical case is that I intend to be playing the piece, and that the further intentions that motivate the basic actions by which I have been doing so are motivated (in turn) by that original intention . . . . In this way, a complex motivational structure of basic actions (like moving one's hands) constitutes the performance of a non-basic action (like playing a piece ofmusic)." (Kieran Setiya, "Explaining Action," 363-4). Also see, Berent Enc , How We Act: Causes, Reasons, and Intentions (Oxford: Clarendon Press, 2003), chs. 2-3, and Searle's discussion of the objects and interrelations of prior intention and intention-in-action in chapter 2 of Intentionality. 16 Where physical action has this general structure, there is no place for practical reason as conceived by the Aristotelian tradition according to which the conclusion of practical reason is an action. Within the framework of the causal theory, the closest thought can come to what happens is: triggering, monitoring, intervening-in-the-progress-by-further-triggering. This leaves 
no room for the relation between the conclusion of practical reasoning and action to be identity; there is no room for an intellectual capacity the exercise of which is itself what happens. In the background of this essay is the hope that it might make some conceptual space for a proper articulation of the Aristotelean tradition.

17 This form of dependence and the need for it to come to a limit has been widely discussed. I am trying to work with a formulation that does not involve, or at least foreground, any specific conception of the individuation of action. Also, my focus is on the specifically intentional case-a series of casually-dependent intentional actions. Unlike, say, Davidson, I am not working up to an articulation of that structure through a conception of the generic structure of doing simply, agency in Davidson's sense. The details of the regress argument I describe are perhaps closest to those found in James Hopkins, "Mental States, Natural Kinds and Psychophysical Laws," Proceedings of the Aristotelian Society, Supplementary Volumes 52 (1978): 221-236. See generally: Jonathan Bennett, "Shooting, Killing and Dying," Canadian Journal of Philosophy 1 (1972): 275-293; Davidson, "Agency" and "Problems in the Explanation of Action," in his Problems of Rationality (New York: Oxford University Press, 2004); Alvin Goldman, “The Individuation of Action,” Journal of Philosophy 68 (1971): 761774; Hornsby, Actions; Judith Jarvis Thomson, “Individuating Actions," Journal of Philosophy 68 (1971): 774-781.

18 The pleasingly hyperbolic idea of posthumous agency is in Davidson: "Arthur may be quite finished with his deed-in fact, he may be dead—when the consequence of his deed makes it a destroying of an aeroplane," (Donald Davidson, "Adverbs of Action," in Essays on Davidson: Actions and Events, eds. B. Vermazen and M. Hintikka [Oxford: Clarendon Press, 1985], 237).

19 I have not tried to pin the attempt to argue that it does on any specific author. Still, I suspect there is a widespread temptation to slide from one to the other (I feel it myself) which stems from an equally widespread fixation on a single sort of means-end connection, namely where the agent acts on a thought of the form "If I do A, I'll do B." In such a case, if all goes well, I'll have done B by doing A where, to borrow some of the Davidsonian apparatus, my A-ing is the same doing as my B-ing. (See Roderick Chisholm, "Some Puzzles about Agency," in The Logical Way of Doing Things, ed. K. Lambert [New Haven: 1969] 209-10, and Alvin Goldman, A Theory of Human Action [Englewood Cliffs: Prentice Hall, 1970], 78.) Of course, we don't just flip switches to illuminate rooms, and push buttons to sink ships, we also break eggs to make omelets, pour concrete to build houses, and write " $\mathrm{f}$ " to write "fool". If I break an egg in order to make an omelet, I must think egg breaking has something to do with omelet making, yet I need not think by breaking an egg I'll make an omelet. I might just act on the thought that egg breaking is a part, phase or condition of omelet making, or even just that it helps with or facilitates omelet making. And, if all goes well, my egg breaking will not be the 
same doing as my omelet making; instead it will be a proper part of that.

20 Aristotle, Nicomachean Ethics (1113a3), eds. Sarah Broadie and Christopher Rowe (Oxford: Oxford University Press, 2002). At times, Berent Enc seems to be moved by similar considerations: "the pattern of practical reasoning presupposes that there are certain things we can do readily. In other words, pressures from the theory of rational deliberation force on us a class of actions to perform, and these actions are such that we do not need to figure out the means for performing them; we can perform them 'forthwith"' (How We Act, 51, my italics). 21 Like Kieran Setiya, I have doubts about whether the argument so characterized captures an absurdity: "There is still the possibility of an infinite series of intelligent actions, with no beginning; if each member of the series is more rapid than its successor, the infinity might even occupy a finite time" (Setiya, "Practical Knowledge," Ethics 118 (2008): 388-409, at 402). Moreover, there is good reason to doubt that it captures Aristotle's idea. After all, he famously defends the thought that movement (kin`esis) incorporates an infinity of sub-movements (Physics Bk. IV, esp. 237a 26-8).

22 For a recent defense of this claim see Setiya's "Practical Knowledge."

23 Aristotle, Nicomachean Ethics, 1140a1-23.

24 Hornsby, Actions, 88.

25 Hornsby, "Semantic Knowledge and Practical Knowledge," 114. Also see her "Knowledge and Abilities in Action."

26 Hornsby, "Semantic Knowledge and Practical Knowledge," 115.

27 I mean decisive for the specific purposes of this essay. I do not doubt the independent interest of practical knowledge and its objects. My complaint is not that there is nothing to these but only that the surrounding discussion has not always kept the illegitimate idea of basic action at a proper distance. Indeed, my aim in unsettling the latter is, in part, to come to a proper understanding of the former. And so, far from being opposed to the concept of a distinct, specifically practical form of knowledge, I see this essay as taking a step toward its comprehension. To ground the idea of practical knowledge we must be able to make sense of it as a form of knowledge. But the view that basic action is the fundamental manifestation of agency threatens to deprive us of that: for, as I suggest in section 5, a basic action falls outside the scope of an agent's knowledge.

28 Terry Penner, "Verbs and the Identity of Actions," in Ryle: A Collection of Critical Essays, O. Wood and G. Pitcher eds., (New York: Doubleday, Anchor Books, 1970), 393-460. 29 For a very different picture see, for example, Hubert Dreyfus, "Overcoming the Myth of the Mental: How Philosophers Can Profit from the Phenomenology of Everyday Experience," Presidential Address, Proceedings and Addresses of the American Philosophical Association 79 (2005): 47-65, and Sean Kelly, "The Logic of Motor Intentional Activity” (ms.). 30 Marx, “Alienated Labour,” 95. 
31 Set against the passage from Marx quoted earlier (endnote 3), the economic metaphors of contemporary action theory are striking: "A chief executive officer can get his employees to do certain tasks without knowing or caring how they do them. Indeed, as we all know, a hierarchical arrangement of executive responsibility is an efficient way to organize command structures. It is also an effective way to design the mechanisms responsible for behavior" (Fred Dretske, Explaining Behavior [Cambridge: MIT Press, 1988], 133); "It is as if the goal directed system commands a package behavior, the way one orders a packed lunch from a hotel for a day's hike, being confident that what goes into the package will be selected by competent personnel" (Enc, HowWe Act, p. 65); "Action is like the corporate enterprise of work performed under management: it's behavior executed under conscious control. And just as the corporate enterprise includes both a basic work activity and the higher-order activity of managing that work ... so full-blooded action comprises both a basic activity and the higherorder activity of controlling it" (David Velleman, "The Possibility of Practical Reason," 192). 32 Some will want to object to (a): walk across the street is a concept of a thing to do, general and repeatable, something I might do any number of times, and thus, something I might have done before. But, in that case, I am walking across again, and have not yet met with success this time. Some will want to object to (b) on similar grounds: having met with earlier success, walking across the street might be, nevertheless, something I am doing later. The reply is also similar: in that case, I am walking across the street again and not still walking across the street. There would be no temptation to raise such difficulties if the relevant specificity were put into the content of the concept, e.g., walk across the street for the first time.

33 This thought is developed further in section 4 of my "Goodness and Desire" (with Matthew Boyle).

34 Aristotle, Metaphysics Theta 6,1048b18-35. There is a large and philosophically rich literature on aspect that has only recently been brought to the core of action theory. I was introduced to the importance of the topic by Thompson's "Na"1ve Action Theory" and also have been helped by G. E. M. Anscombe, "Before and After," Philosophical Review 73 (1964): 3-24, Antony Galton; The Logic of Aspect (Oxford: Oxford University Press, 1984); Alexander P. D. Mourelatos, "Events, Processes, and States," Linguistics and Philosophy 2 (1978): 415434. Terence Parsons, Events in the Semantics of English (Cambridge, MA: MIT Press, 1990); Penner, "Verbs and the Identity of Actions"; Sebastian R" odl, Categories of the Temporal: An Inquiry into the Form of the Finite Intellect (Cambridge, Mass.: Harvard University Press, 2012); and Sarah Waterlow, Nature, Change and Agency in Aristotle's Physics (Oxford: Oxford University Press, 1982).

35 Some will object that not everything done intentionally has the temporal structure of kin ${ }^{-}$esis: neither instantaneous action (start, stop, arrive, win) nor Aristotle's energeia (see, think, live well) give application to the idea of completion yet unattained. That is correct. And this 
essay does not address directly whether there must or can be action with some other temporal structure that is basic. I am not troubled by this limitation. In the first place, I would consider the essay a success were it to establish that if basic action is to be anything at all it cannot be durative and telic. Second, I would argue elsewhere for the conceptual and not merely statistical priority of the representation of durative telic action in thought and speech: the fundamental case of action has our features.

36 Aristotle, EN 1173a32-1173b5.

37 Aristotle, EN 1174a22-24.

38 See Physics 236a13-26 where Aristotle argues that there is no first moment of change: if $\mathrm{X}$ is doing $\mathrm{A}, \mathrm{X} \operatorname{did} \mathrm{A} *$.

39 It bears repeated emphasis that the distinction of aspect and the temporal structure articulated through it have nothing especially to do with action. Above I used the schematic sentences "X is doing A," "X was doing A," and "X did A" to mark this distinction and thereby to put in place the abstract category of kin" esis or movement. Given the great diversity of uses of "to do" in English, especially its (agency-implying) use as a lexical verb meaning something like "to perform," I should remark that here it functions only as a dummy (semantically empty) auxiliary verb, the point of which is to receive distinctions of aspect. There are many ways to express aspect in natural language. And there are other schematic sentences which could equally serve to mark the distinction, for example, "X is $\varphi$-ing" " $\mathrm{X}$ was $\varphi$-ing" and "X $\varphi$-ed." Perhaps these bring into better focus the abstractness of the aspectual distinction and the category of movement articulated through it. Once in focus, it is easy to wonder what bearing our reflections on the temporality of movement could have on the legitimacy of the notion of basic action. To avoid misunderstanding, it is important to emphasize that I am not arguing that the aspectual distinction entails divisibility into phases united though means-end rationality (which is certainly false), nor that the aspectual distinction when applied to action entails divisibility into phases, themselves actions done for the sake of the whole (which I do think is the case). My ambition is only to describe what a basic action would be in light of this abstract temporal structure, the details of which, I suggested above, are easily obscured by certain features of philosophical practice and writing displayed in the literature. My thought is simply that having seen what a basic action would have to be, and how it would have to relate to the non-basic actions of which it is supposed to form a part, we should find it difficult to recognize basic action as action at all.

40 As we saw above in the discussion of the regress of procedural knowledge, this can be so even where there is no distinct, generic action type which characterizes these subordinate activities: my moving from a to $\mathrm{b}$ involves my moving from a to $\mathrm{c}$ (a point between $\mathrm{a}$ and $\mathrm{b}$ ) and moving from $\mathrm{c}$ to $\mathrm{d}$ (a point between $\mathrm{c}$ and $\mathrm{b}$ ). This idea, too, is Aristotle's: "For if locomotion is movement from one place to another, there are different forms of this too, i.e. flying, walking, 
leaping, and so on; but there are not only these divisions, but divisions in walking itself, since the where from/where to is not the same thing for a race-track and for a part of it, or for one part and for another; nor is crossing this line the same as crossing that one; for one is not only traversing a line, but a line that also has a location, and this line has a different location from that one" (EN 1174a30-1174b3).

41 Enc $_{s}$, How We Act, p. 71.

42 I do not mean to suggest that the power of a human agent is without limit. Finite agency presupposes something other than itself, whether background conditions (the solid ground underfoot when walking to Thebes) or raw material (the sand out of which I build my sandcastle), and this world of independent things can be uncooperative, frustrating even the best laid plans. Indeed, a fundamental task for the philosophy of action is to reconcile rational agency's claim to genuine authority over what happens with such limitations. (For recent discussion of the difficulty see Christine Korsgaard, Self-Constitution: Agency, Identity, and Integrity [Oxford: Oxford University Press, 2009], 84-90, and Sebastian R" odl, "Two Forms of Practical Knowledge and their Unity," in Essays on Anscombe's Intention, ch. 8. But we do not effect the reconciliation by abandoning the aspiration to such authority, to being the cause as opposed to a contributing factor, or again to being able to say with Brian O’Shaughnessy, "We are ultimate sources of change in the environment in a way a river or hurricane is not. A chair or table is a kind of gift to the universe as a whole, as if from another God, certainly from another creator. I actively brought it into existence. For the truth of the matter is: that I did it; I alone; and I did all of it" (The Will: A Dual Aspect Theory, Vol. II, (Cambridge, England: Cambridge University Press, 1980), 2.

43 Marx, Capital, vol. 1, trans. Ben Fowkes (New York: Vintage Books, 1977), 300. 44 Setiya, Reasons without Rationalism, 32. The reply to Harry Frankfurt's well-known objection to the causal theory of action is similar: the causes distinctive of action exert an ongoing guidance. Frankfurt complained that the causal theory distinguishes between actions and mere movements solely in terms of their antecedent causes, thus treating them as intrinsically indistinguishable. This complaint is similar in spirit to the one I have raised against basic action. But it is not the same. Although Frankfurt frequently says the distinguishing feature of action - that it is guided by the subject — must be something that is intrinsic to the progress of the action, his own proposal for what a movement's being guided consists in shows that it is enough for a feature to be intrinsic that it is possessed at the same time as the action is underway. Indeed, at the end of the day, Frankfurt defends a version of the causal theory (action is a mere event plus further conditions) ("The Problem of Action," 159). It should not be surprising, then, that he is also friendly to the idea of basic action (ibid., p. 160). Now, those developing a version of the causal theory have been happy to take Frankfurt's point: the causes of action are not merely ballistic. And I am suggesting that no refinement of the causal theory can restore the 
temporality of agency if the notion of basic action is left in place.

45 I cannot consider the matter here, but I do not see how the idea of a cause that sustains can help to quiet the worry I've raised about basic action. What goes missing in basic action is a role for the self-conscious subject in bringing things progressively closer to a determinate end. How can it help to think that the subject does not merely launch some process but also keeps that process going, not going anywhere in particular, just on-and-on? 46 Randolph Clarke, "Skilled Activity and the Causal Theory of Action," Philosophy and Phenomenological Research 80 (2010): 523-55, at 538.

47 Joseph Raz, "Reasons: Explanatory and Normative," in his From Normativity to Responsibility (New York: Oxford University Press, 2011), 31-32. I do not mean to attribute to Raz a position on basic action. The passage is simply a sharp presentation of a widespread conception of guidance, one that dates back to the beginnings of cybernetics. See A. Rosenblueth, N. Wiener, and J. Bigelow, "Behaviour, Purpose, and Teleology," Philosophy of Science 10 (1943): 18-24, and Norbert Wiener, Cybernetics (New York: MIT Press, 1961). 48 Cf. Kevin Falvey, "Knowledge in Intention,” Philosophical Studies 99 (2000): 21-44. 49 J. David Velleman, Practical Reflection (Stanford: CSLI Publications, 2007), xiii. 